\title{
SMART syndrome: a late reversible complication of radiotherapy
}

\author{
Síndrome SMART: uma complicação tardia reversível da radioterapia \\ Fabio de Vilhena Diniz', Laura Cardia Gomes Lopes², Luiz Henrique Martins Castro², Ricardo Nitrini², \\ Claudia da Costa Leite', Leandro Tavares Lucato
}

A 43-year-old female had a cerebellar pilocytic astrocytoma operated 27 years ago. Reoperation and radiation therapy were employed in a recurrence 13 years ago. One week before admission, progressive drowsiness, disorientation in time and space, slurred speech and worsening of a residual right hemiparesis begun. Cerebrospinal fluid (CSF) analysis and electroencephalography (EEG) were unremarkable. She improved without specific therapy.
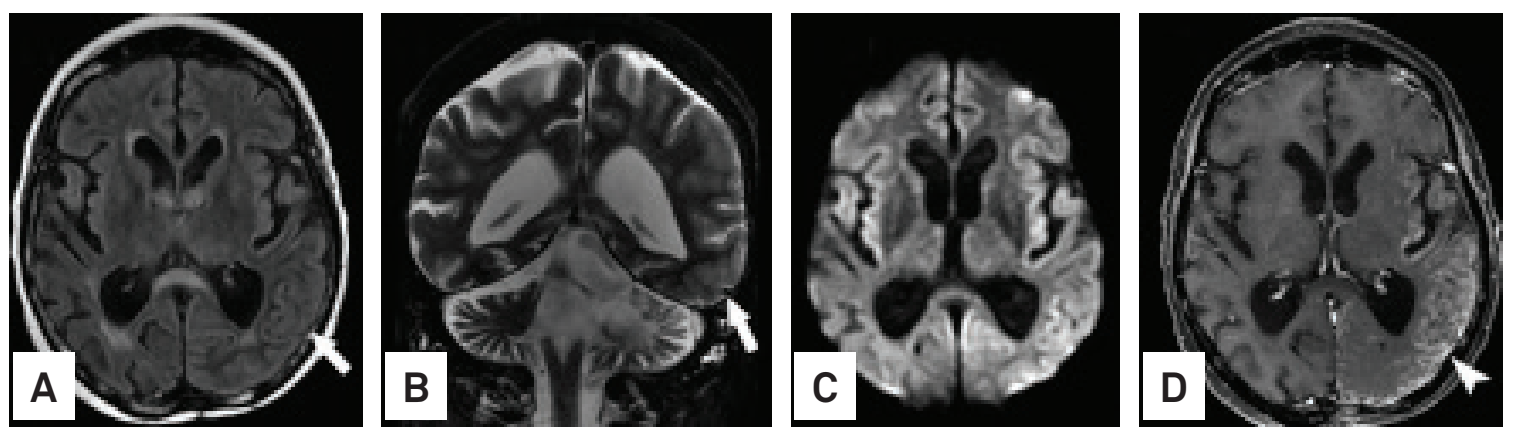

Fig 1. Magnetic resonance (MR) exam obtained in the beginning of the clinical picture. Axial FLAIR (A) and coronal T2-weighted (B) images disclose slight cortical hyperintensity in the left insula, temporal and parietooccipital regions (arrows), which presents intense gyriform enhancement in the corresponding axial T1-weighted post gadolinium image (arrowhead in D). There is also slight cortical hyperintensity in diffusion-weighted image (C), but without clear reduced diffusion in apparent diffusion coefficients map (not shown). Notice also postoperative changes in the left cerebellar hemisphere, seen in coronal T2-weighted image (B), and nonspecific hyperintense periventricular lesions in axial FLAIR image (A).
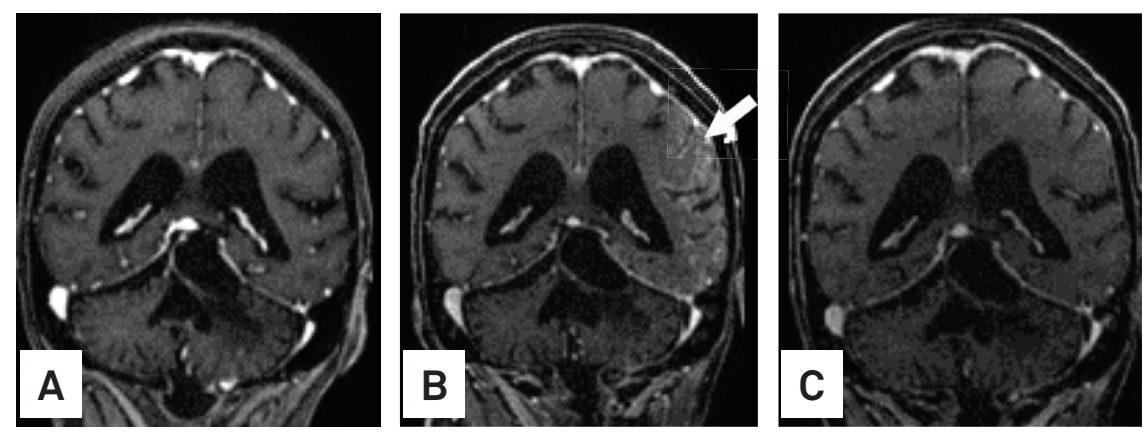

Fig 2. Coronal reformatted images from post contrast 3D-SPGR images obtained in three distinct time frames. (A) Image obtained 16 months before the beginning of the acute clinical findings demonstrates only cerebellar postoperative changes, in a regular follow-up exam. (B) Image obtained from the same exam as Fig 1, showing the intense gyriform enhancement in the left temporal and parietooccipital regions (arrow). (C) After 14 days, a new magnetic resonance (MR) exam shows no abnormal enhancement.

\footnotetext{
'Department of Radiology, Hospital das Clínicas da Faculdade de Medicina da Universidade de São Paulo (HCFMUSP), São Paulo SP, Brazil; ${ }^{2}$ Department of Neurology, HCFMUSP, São Paulo SP, Brazil.

Correspondence: Fabio de Vilhena Diniz; Avenida Dr. Enéas C. Aguiar 255/5084; 05403-000 São Paulo SP - Brasil; E-mail:fvdiniz@yahoo.com.br Conflict of interest: There is no conflict of interest to declare.

Received 05 October 2012; Received in final form 10 December 2012; Accepted 17 December 2012.
} 


\section{References}

1. Bartleson JD, Krecke KN, O’Neill BP, Brown PD. Reversible, strokelike migraine attacks in patients with previous radiation therapy. Neuro Oncolo 2003;2:121-127.

2. Black DF, Bartleson JD, Bell ML, Lachance DH. SMART: stroke-like migraine attacks after radiation therapy. Cephalagia 2006;26:1137-1142.
3. Lachance DH, Black DF, Bartleson JD. SMART: stroke-like migraine attacks after radiation therapy. Neurology 2005;64:A220.

4. Murthy SN, Cohen ME. Pseudomigraine with prolonged aphasia in a child with cranial irradiation for medulloblastoma. J Child Neurol 2002;17:134-138 